TRIADIK

ISSN (print): 0853-8301; ISSN (online): 2745-777X

Available online at https://ejournal.unib.ac.id/index.php/triadik

DOI: https://doi.org/10.33369/triadik.v19i1.16463

page: $34-42$

\title{
PENGARUH LAYANAN INFORMASI DENGAN MEDIA ICT UNTUK MENINGKATKAN PEMAHAMAN ARAH PILIHAN KARIER SISWA KELAS X IPS SMAN 4 KOTA BENGKULU
}

\author{
Risa Dwi Ariani, Syahriman, Vira Afriyati \\ Universitas Bengkulu \\ Korespondensi: risadwiariani4@gmail.com
}

\begin{abstract}
Abstrak
Latar belakang penelitian ini dilakukan karena kurangnya pemahaman siswa mengenai arah pilihan karier. Penelitian ini bertujuan untuk mendeskripsikan pengaruh layanan informasi dengan media ICT untuk meningkatkan pemahaman arah pilihan karier siswa.Metode yang digunakan adalah eksperimen dengan desain one-group, pre-test-post-test design. Sampel dalam penelitian ini berjumlah 30 orang siswa. Prosedur pengambilan sampel menggunakan cluster random sampling. Teknik pengumpulan data menggunakan angket. Teknik analisis data menggunakanuji T. Hasil penelitian menunjukkan bahwa tingkat pemahaman arah pilihan karier siswa meningkat setelah diberikan layanan informasi dengan media ICT.Hal ini ditunjukkan dari hasil uji perbedaan pre-test dan post-test dengan nilai $\mathrm{t}_{\text {hitung }}=24,254>\mathrm{t}_{\text {tabel }}=2,733$ dan signifikasi 0,000 $(\mathrm{p}<0,05)$, sehingga hipotesis $\left(\mathrm{H}_{0}\right)$ ditolak dan $\left(\mathrm{H}_{a}\right)$ diterima. Artinya terdapat pengaruh yang signifikan terhadap tingkat pemahaman arah pilihan karier siswa sebelum dan sesudah diberikan layanan informasi dengan media $I C T$.
\end{abstract}

Kata Kunci: arah pilihan karier, layanan informasi dengan media ICT.

\section{Abstract}

The background of this research was conducted because of the students' lack of understanding of the direction of career choices. This study aims to describe the effect of information services usingmedia ICT to improve students' understanding of the direction of career choices. The method used was an experiment withdesign one-group, pre-test-post-test design. The sample in this study amounted to 30 students. The sampling procedure used cluster random sampling. The data collection technique used a questionnaire. The data analysis technique used the T-test. The results showed that the level of understanding of the direction of student career choices increased after being given information services with media ICT. It is shown from the test results differences in pre-test and the post-test with a value of $t_{\text {count }}=24,254>t_{\text {table }}=2,733$ and the significance is $0,000(p<0,05)$, so hypotesis $\left(H_{0}\right)$ rejected and $\left(H_{a}\right)$ accepted. This means that there is a significant influence on the level of understanding of the direction of student career choices before and after being given information services usingmedia ICT.

Keyword:career choice direction, information service with media ICT 


\section{Pendahuluan}

Masa remaja merupakan masa dituntutnya seorang remaja untuk memenuhi tugas-tugas perkembangan. Salah satunya yaitu memilih dan menentukan karier atau pekerjaan yang sesuai dengan keinginan dan potensi yang dimiliki. Remaja saat ini masih banyak belum mampu untuk memikirkan tujuan apa yang akan ia ambil ketika mengkhiri bangku Sekolah Menengah Atas (SMA). Hal itu dikarenakan kurangnya pemahaman mengenai dunia karier, untuk mendapatkan pemahaman tersebut peran pendidikan sangat diperlukan guna mengarahkan siswa lebih memahami mengenai dunia karier, agar tidak terjadi timbulnya kesalahan dalam pemilihan karier yang akan dipilih dimasa yang akan datang.

Menurut Undang-Undang No. 20 tahun 2003 Pasal 1 ayat 1 (2006: 5), "Pendidikan adalah usaha sadar dan terencana untuk mewujudkan suasana belajar dan proses pembelajaran agar peserta didik secara aktif mengembangkan potensi dirinya untuk memiliki kekuatan spiritual keagamaan, pengendalian diri, kepribadian, kecerdasan, akhlak mulia, serta keterampilan yang diperlukan dirinya, masyarakat, bangsa dan negara". Pendidikan merupakan sarana bagi siswa untuk mendapatkan ilmu pengetahuan, mengembangkan kreativitas, juga sebagai sarana untuk mendapatkan berbagai informasi guna menjadi arahan untuk bekal yang akan dipilih dimasa mendatang. Maka dari itu keputusan memilih suatu karier, pekerjaan, serta cita-cita bagi seseorang sangat berkaitan erat dengan dunia pendidikan yang harus ditempuh dan diselesaikannya.

Menurut Indaswari,dkk (dalam Fadli, 2017: 74) karier diciptakan, dibina dan dikembangkan melalui dan selama kehidupan. Semuanya itu berkaitan erat dengan seberapa baik seseorang mengelola diri sendiri, memahami orang lain dan lingkungan, serta berhubungan dengan orang lain dan lingkungannya (Yusuf, A. M (dalam Fadli, 2017: 74). Hal ini berarti karier seseorang ditentukan dari pemahaman diri sendiri, pemahaman orang lain dan lingkungan sekitar.

Bimbingan dan konseling merupakan bagian integral dari dunia pendidikan yang secara sadar memposisikan kemampuan siswa untuk mengeksplorasi, memilih, merencanakan dan mengambil keputusan untuk meraih masa depannya (Khairun, 2016: 2). Guru BK dapat menjadi sarana untuk memberikan arahan kepada siswa untuk menentukan karier sesuai dengan potensi yang siswa/i miliki. Pilihan karier dan langkah-langkah pendidikan dan pelatihan yang tepat akan mengantar seseorang menjadi individu yang mempunyai daya saing dalam bursa kerja (Zulkaida, 2007: 1). Sebaliknya, rendahnya pemahaman karier dapat menyebabkan kesalahan dalam mengambil keputusan karier, termasuk kesalahan dalam menentukan pendidikan lanjutan (Zulkaida, 2007: 1).

Siswa dalam menjalani kehidupannya selalu mengalami hambatanhambatan termasuk hambatan dalam menentukan arah pilihan karier yang akan dipilihnya nanti. Berdasarkan penelitian yang telah dilakukan oleh Febri Yani Falentini, dkk tahun 2013 hambatan yang banyak ditemui siswa dalam menentukan arah pilihan karier adalah dari teman sebaya yaitu sebesar $75,76 \%$ dan hambatan yang sedikit ditemui siswa adalah dari faktor 
keluarga yaitu 64,04\%. Hal itu menunjukkan banyaknya masukan dan dorongan dari teman-teman terkadang membuat siswa ragu dengan pilihannya sendiri karena mereka lebih mempertimbangkan masukan tersebut dari pada pilihan mereka sendiri. Banyak juga siswa yang ragu dalam memilih arah pilihan karier karena hasil belajar kurang memuaskan atau keadaan keluarga yang kurang mendukung, oleh sebab itu banyak siswa yang tidak bisa menentukan arah pilihan karier mereka. Maka dari itu untuk menambah pemahaman siswa mengenai karier dalam penelitian ini digunakan layanan informasi.

Menurut Hidayati (2015: 3) layanan informasi merupakan layanan yang memungkinan peserta didik menerima dan memahami berbagai informasi (seperti; informasi belajar, pergaulan, karier, pendidikan lanjutan). Layanan ini dapat dilaksanakan secara klasikal maupun kelompok dengan beberapa variasi metode.

Variasi metode membuat layanan informasi tidak terkesan monoton. Penyampaian materi yang monoton menyebabkan siswa merasa jenuh dan kurang bersemangat untuk menerima informasi. Hal tersebut membuat siswa merasa kesulitan untuk memahami informasi yang pada akhirnya akan membuat mereka sulit memahami masa depan karir yang akan mereka hadapi (Hasanah, 2014: 543). Dalam penelitian ini media yang digunakan yaitu media Information and Communication Technologies (ICT). Media pembelajaran yang berbasis ICT adalah alat yang digunakan untuk mengolah, mentransfer dan memuat data atau informasi dari perangkat yang satu dengan perangkat yang lainnya, sehingga proses dalam mengkomunikasikan setiap data atau informasi mudah untuk dipahami dan dicerna dalam proses pembelajaran (Komariah, 2016: 83). Pemanfaatan teknologi informasi dalam berbagai kesempatan layanan bimbingan dan konseling, pada umumnya menggunakan dua metode yaitu online dan offline (Pranoto, dkk, 2017:17).

Menurut Pranoto, dkk, (2017: 17) layanan dalam bentuk online dilakukan melalui format jarak jauh,sedangkan penggunaan teknologi dalam layanan bimbingan dan konseling dengan metode offline (tidak tersambung dengan internet maupun media komunikasi jarak jauh yang lain) misalnya dengan menggunakan beberapa program komputer seperti microsoft power pointt, video player dan beberapa media interaktif lain dalam melayani siswa (Pranoto, dkk, 2017: 19). Media ICT yang digunakan dalam penelitian ini yaitu pemberian layanan informasi melalui metode online berupa grup whatssapp yang diharapkan dapat lebih memudahkan siswa untuk berdiskusi dan sharing mengenai berbagai hal yang dapat meningkatkan pemahaman dan kemampuan untuk lebih mempersiapkan diri menghadapi dunia karier.

Berdasarkan permasalahan tersebut, rumusan masalah dalam penelitian ini adalah bagaimana pemahaman arah pilihan karier siswa sebelum diberikan layananinformasi dengan media ICT, bagaimana pemahaman arah pilihan karier siswa setelah diberikan layanan informasi dengan media ICT, dan bagaimana pengaruh layanan informasi dengan media ICT untuk meningkatkan pemahaman arah pilihan karier siswa kelas X IPS SMAN 4 Kota Bengkulu.

\section{Metode Penelitian}

Desain penelitian yang dilakukan dalam penelitian ini adalah one-group 
pre-test-post-test design, yaitu terdapat pre-test sebelum diberikan penelitian dan post-test setelah diberikan layanan. Dalam penelitian ini dilakukan sebanyak 2 kali pengukuran yaitu pengukuran angket pemilihan karier sebelum pemberian layanan informasi dengan media $I C T$, dan pengukuran angket pemilihan karier setelah layanan informasi dengan media ICT dengan menggunakan instrument yang sama yaitu skala arah pilihan karier siswa.

Sampel dalam penelitian ini adalah 1 kelas (X IPS 3) dari keseluruhan populasi yang dipilih menggunakan teknik cluster random sampling. Teknik cluster random sampling merupakan teknik pengambilan sampel secara acak melalui kelompok kelas tertentu dengan jumlah yang besar. Langkah sebelumnya yang dilakukan adalah merandom seluruh populasi yaitu seluruh kelas X IPS SMAN 4 Kota Bengkulu. Kemudian berdasarkan hasil random selanjutnya terpilihlah satu kelas yang berjumlah 30 orang siswa yaitu kelas X IPS 3. Setelah diperoleh hasil random tersebut barulah peneliti memulai penelitian pada kelas tersebut dan memberikan layanan informasi dengan media $I C T$.

Teknik pengumpulan data pada penelitian ini menggunakan angket/kuesioner arah pilihan karier berupa angket skala likert. Penggunaan skala likert dalam penelitian ini untuk mengukur pendapat siswa mengenai arah pilihan karier. Bentuk skala likert yaitu bentuk pernyataan tertutup dengan beberapa alternatif jawaban.

Uji validitas dilakukan dengan beberapa prosedur. Pertama, angket diuji validitasnya oleh beberapa orang ahli dibidang bimbingan dan konseling. Setelah angket dinyatakan valid oleh para ahli, kemudian dilaksanakan uji coba angket kepada kelas yang tidak termasuk dalam sampel. Angket uji coba yang telah disebar selanjutnya diuji validitas menggunakan scale pada Statistical Packages for sosial science (SPSS) versi 22.0. Dalam penelitian ini uji reliabilitas menggunakan SPSS versi 22.0 dengan rumus Alpha Cronbach's. Berdasarkan hasil uji reliabilitas diperoleh Cronbach's Alpha sebesar 0,890> 0,6, Oleh karena itu, kuesioner arah pilihan karier dapat dikatakan reliabilitas yang baik.

Uji hipotesis dalam penelitian ini menggunakan rumus uji-t. Pengujian dilakukan dengan menggunakan bantuan SPSS versi 22.0 metode analisis data statistic compare means dengan rumus Paired Samples T Test. Kriteria pengujian hipotesis menggunakan uji-t jika nilai Sig (2-tailed) $<0,05$ maka (Ho) ditolak dan (Ha) diterima.Berdasarkan hasil uji tersebut, nilai T adalah -24,254 dan taraf signifikasinya adalah 0.000, Ho (ditolak) dan $\mathrm{Ha}$ (diterima), artinya terdapat pengaruh layanan informasi dengan media ICT untuk meningkatkan pemahaman arah pilihan karier siswa kelas X IPS SMAN 4 Kota Bengkulu.

Perlakuan yang diberikan dalam penelitian ini adalah layanan informasi dengan media ICT sebanyak 6 kali pertemuan. Setiap pertemuan membahas materi yang berkaitan dengan arah pilihan karier siswa.
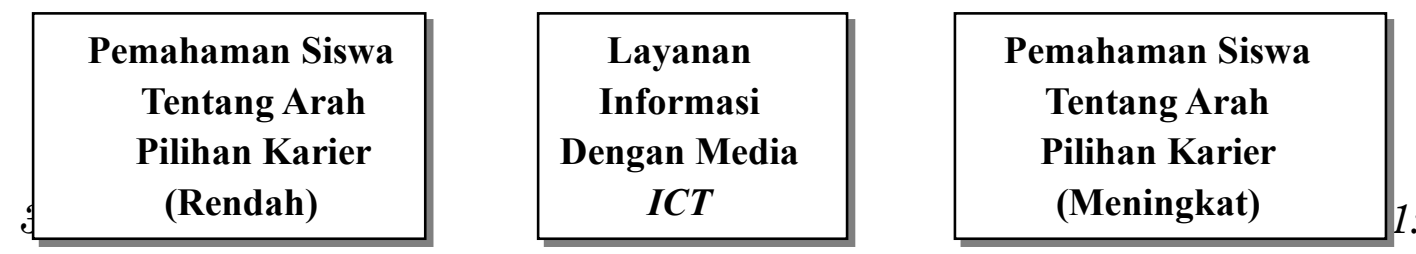


\section{$\longrightarrow \underset{\text { Gambar 1 }}{\longrightarrow}$}

Berdasarkan gambar 1 di atas, dapat dilihat bahwa pemahaman arah pilihan karier siswa dapat meningkat dengan diberikan layanan informasi dengan media ICT dan pilihan karier siswa menjadi lebih terarah. Dari pemahaman arah pilihan karier siswa yang rendah menjadi meningkat dengan cara pemberian layanan informasi. Hal ini menunjukkan keterkaitan meningkat atau tidaknya pemahaman siswa mengenai arah pilihan karier melalui informasi yang diperoleh.

\section{Hasil dan Pembahasan}

Menurut Azwar (2012: 15) penentuan kategori didasari atas asumsi bahwa skor populasi subjek terdistribusi secara normal. Dalam menentukan kategori perolehan skor siswa diawali dengan mencari mean dan standar deviasi dengan menggunakan (SPSS) versi 22,0. Hasil data dalam penelitian untuk pengukuran diperoleh data mean sebesar 87,5, standar deviasi sebesar 17,5, dengan skor minimum sebesar 35 dan skor maksimum sebesar 140. Pengukuran menggunakan 5 kategori. Kategori tersebut adalah sangat tinggi, tinggi, sedang, rendah, dan sangat rendah.

\section{Tabel 1}

Frekuensi Skor Pre-test

\begin{tabular}{llrr}
\hline Interval & Kategori & \multicolumn{2}{c}{ Frekuensi } \\
\hline & Sangat & & \\
& Tinggi & & \\
& Tinggi & 0 & 0 \\
$96-112$ & Sedang & 0 & 0 \\
$78-95$ & Rendah & 5 & $17 \%$ \\
$61-77$ & Sangat & 25 & $83 \%$ \\
$60 \leq$ & Rendah & 0 & $0 \%$ \\
\hline
\end{tabular}

Berdasarkan tabel 1 diatas, dapat diketahui bahwa siswa yang memiliki arah pilihan karier dengan kategori sedang (78-95) sebanyak 5 orang dengan presentase 17\%, dan siswa dengan kategori rendah (61-77) sebanyak 25 orang dengan presentase $83 \%$.

Berdasarkan hasil data pre-test tersebut, peneliti dapat mengetahui siswa yang memiliki skor sedang dan rendah. Langkah selanjutnya, peneliti memberikan layanan informasi dengan media ICT kepada sampel yang telah diberikan angket pre-test untuk melihat apakah ada atau tidak adanya peningkatan pemahaman arah pilihan karier siswa setelah diberikan layanan informasi dengan media ICT. Setelah diberikannya perlakuan (layanan) sebanyak 6 kali pertemuan secara online, peneliti melakukan post-test, dengan memberikan soal tes yang sama pada saat pre-test.

Tabel 2

Frekuensi Skor Post-test 


\begin{tabular}{llrr}
\hline Interval & \multicolumn{1}{c}{ Kategori } & Frekuensi & Presentase \\
\hline & & & \\
$\leq 113$ & Sangat Tinggi & 0 & 0 \\
$96-112$ & Tinggi & 28 & $93 \%$ \\
$78-95$ & Sedang & 2 & $7 \%$ \\
$61-77$ & Rendah & 0 & $0 \%$ \\
$60 \leq$ & Sangat Rendah & 0 & $0 \%$ \\
\hline
\end{tabular}

Berdasarkan tabel 2 diatas, dapat diketahui bahwa siswa yang memiliki arah pilihan karier dengan kategori tinggi (96-112) sebanyak 28 orang dengan presentase 93\%, dan siswa dengan kategori sedang (78-95) sebanyak 2 orang dengan presentase $7 \%$. Jika nilai rata-rata post-test termasuk dalam kategori tinggi maka terdapat pengaruh peningkatan pemahaman arah pilihan karier siswa setelah diberikan layanan informasi dengan media ICT.

\section{Tabel 3}

\begin{tabular}{|c|c|c|c|c|c|}
\hline \multirow[b]{2}{*}{$\begin{array}{c}\text { Respon } \\
\text { den }\end{array}$} & \multicolumn{2}{|c|}{ Pre-test } & \multicolumn{2}{|c|}{ Post-test } & \multirow[b]{2}{*}{$\begin{array}{r}\text { Kenai } \\
\text { kan }\end{array}$} \\
\hline & Skor & $\begin{array}{c}\text { Katego } \\
\text { ri }\end{array}$ & Skor & $\begin{array}{c}\text { Katego } \\
\text { ri }\end{array}$ & \\
\hline $\mathrm{AP}$ & 77 & Rendah & 106 & Tinggi & 29 \\
\hline ASP & 66 & Rendah & 95 & Sedang & 29 \\
\hline $\mathrm{AAG}$ & 69 & Rendah & 112 & Tinggi & 43 \\
\hline APS & 70 & Rendah & 111 & Tinggi & 41 \\
\hline $\mathrm{BS}$ & 77 & Rendah & 111 & Tinggi & 34 \\
\hline $\mathrm{CE}$ & 69 & Rendah & 110 & Tinggi & 41 \\
\hline $\mathrm{DA}$ & 75 & Rendah & 112 & Tinggi & 37 \\
\hline DDS & 73 & Rendah & 109 & Tinggi & 36 \\
\hline EPR & 77 & Rendah & 112 & Tinggi & 35 \\
\hline $\mathrm{FH}$ & 74 & Rendah & 111 & Tinggi & 37 \\
\hline FJS & 73 & Rendah & 110 & Tinggi & 37 \\
\hline $\mathrm{FN}$ & 74 & Rendah & 112 & Tinggi & 38 \\
\hline FAA & 71 & Rendah & 98 & Tinggi & 27 \\
\hline FRA & 76 & Rendah & 112 & Tinggi & 36 \\
\hline $\mathrm{FH}$ & 77 & Rendah & 100 & Tinggi & 23 \\
\hline FLN & 68 & Rendah & 95 & Sedang & 27 \\
\hline $\mathrm{G}$ & 84 & Sedang & 109 & Tinggi & 25 \\
\hline HA & 77 & Rendah & 106 & Tinggi & 29 \\
\hline LM & 72 & Rendah & 100 & Tinggi & 28 \\
\hline $\mathrm{MNH}$ & 92 & Sedang & 112 & Tinggi & 20 \\
\hline MSS & 93 & Sedang & 110 & Tinggi & 17 \\
\hline $\mathrm{OY}$ & 74 & Rendah & 111 & Tinggi & 37 \\
\hline PSA & 77 & Rendah & 101 & Tinggi & 24 \\
\hline $\mathrm{R}$ & 76 & Rendah & 105 & Tinggi & 30 \\
\hline $\mathrm{RS}$ & 75 & Rendah & 112 & Tinggi & 37 \\
\hline RMA & 81 & Sedang & 105 & Tinggi & 24 \\
\hline $\mathrm{RR}$ & 74 & Rendah & 110 & Tinggi & 36 \\
\hline $\mathrm{RM}$ & 93 & Sedang & 112 & Tinggi & 19 \\
\hline $\mathrm{SAP}$ & 77 & Rendah & 111 & Tinggi & 34 \\
\hline SRN & 76 & Rendah & 101 & Tinggi & 25 \\
\hline
\end{tabular}




\begin{tabular}{cccccc} 
Jumlah & 2287 & & 3221 & & 925 \\
$\begin{array}{c}\text { Tertingg } \\
\text { i }\end{array}$ & 93 & Sedang & 112 & Tinggi & 43 \\
$\begin{array}{c}\text { Terenda } \\
\text { h }\end{array}$ & 66 & Rendah & 95 & Sedang & 17 \\
$\begin{array}{c}\text { Rata- } \\
\text { rata }\end{array}$ & 76,2 & Rendah & 107,4 & Tinggi & 30,8 \\
\hline
\end{tabular}

Berdasarkan tabel 3, 30 siswa yang telah diberikan perlakuan berupa layanan informasi dengan media ICT mengalami kenaikan skor pada hasil post-test. Terlihat pada tabel pre-test rata-rata siswa memiliki pemahaman arah pilihan karier yang tergolong dalam kategori rendah dengan rata-rata skor 76,2. Namun setelah diberikan perlakuanmengalami kenaikan skor terlihat pada tabel post-test rata-rata siswa memiliki pemahaman arah pilihan karier yang tergolong dalam kategori tinggi dengan rata-rata skor menjadi 107,4. Hal itu dikarenakan siswa lebih memahami arah pilihan kariernya setelah diberikan layanan informasi dengan media ICT.

Hasil uji hipotesis yang telah dilakukan, terjadi perubahan pemahaman arah pilihan karier siswa pada pre-test dan post-test. Adapun hasil uji hipotesis yang diperoleh menggunakan SPSS versi 22.Dengan menggunakan uji $T$ test atau uji $\mathrm{T}$ adalah sebagai berikut:

\section{Tabel 4}

Hasil Perhitungan Uji-t

\begin{tabular}{ccc}
\hline & $T$ & $\begin{array}{l}\text { Sig. }(2- \\
\text { tailed })\end{array}$ \\
\hline Pre-test-Post- & $-24,254$ &, 000
\end{tabular}

Paired Sample Test digunakan untuk mengetahui adanya perbedaan skor sebelum dan sesudah diberikan layanan informasi dengan media ICT. Berdasarkan tabel 4 diperoleh hasil $\mathrm{P}=0,000$. $\mathrm{P}<0,05$ sehingga $\left(\mathrm{H}_{0}\right)$ ditolak dan $\left(\mathrm{H}_{a}\right)$ diterima. Dari hasil tersebut, dapat disimpulkan bahwa terdapat pengaruh layanan informasi dengan media ICT untuk meningkatkan pemahaman arah pilihan karier siswa.

Sebelum dilakukan layanan informasi pemahaman siswa mengenai arah pilihan karier masih banyak yang tergolong rendah, dan juga belum mengetahui arah pilihan karier yang akan dipilih ketika lulus SMA karena kurangnya informasi yang dimiliki mengenai dunia karier. Setelah diberikan layanan informasi dengan media ICT online via grup whatsapp, terjadi peningkatan skor pemahaman arah pilihan karier siswa yang tergolong dalam kategori tinggi.

Pada hasil post-test terdapat beberapa angka yang meningkat tinggi, dikarenakan meningkatnya pemahaman siswa mengenai arah pilihan karier yang didukung pemberian materi pada layanan informasi. Ada pula tingkat kenaikan skor siswa yang rendah, itu dikarenakan tingkat kemampuan siswa dalam memahami materi yang disampaikan kurang dicerna dan dipahami oleh siswa tersebut.

Layanan informasi dengan media ICT lebih mempermudah dan menyenangkan bagi siswa dalam pelaksanaan layanan, siswa diberikan materi sesuai dengan tema yang tercantum dalam kisi-kisi angket, terkini dan sesuai dengan kebutuhan yang akan dihadapi ketika lulus SMA, juga mendapatkan gambaran informasi tentang pilihan karier yang akan menjadi 
keputusan untuk dipilih serta tidak mengalami salah pilihan jurusan dan karier dimasa yang akan datang. Hal tersebut dapat menunjukkan bahwa layanan informasi dengan media ICT dapat meningkatkan pemahaman arah pilihan karier siswa.

\section{Simpulan}

Berdasarkan hasil analisis data pada penelitian mengenai pengaruh layanan informasi dengan media ICT untuk meningkatkan pemahaman arah pilihan karier siwa dapat diambil kesimpulan bahwa, tingkat pemahaman arah pilihan karier siswa sebelum diberikan layanan informasi dengan media ICT dari skor pre-test tergolong kategori rendah, tingkat pemahaman arah pilihan karier siswa setelah diberikan layanan informasi dengan media ICT dari skor post-test tergolong kategori tinggi, dan adanya peran positif dan signifikansi dari layanan informasi dengan media ICT dalam meningkatkan pemahaman arah pilihan karier siswa. Hal ini dibuktikan berdasarkan hasil analisis data uji hipotesis $\mathrm{H}_{0}$ yang menyatakan tidak terdapat pengaruh layanan informasi dengan media ICT untuk meningkatkan pemahaman arah pilihan karier siswa ditolak dan Ha yang menyatakan terdapat pengaruh layanan informasi dengan media ICT untuk meningkatkan pemahaman arah pilihan karier siswa diterima. Bagi peneliti selanjutnya, sebaiknya lebih mengkaji banyak sumber dan referensi yang terkait dengan arah pilihan karier agar hasil penelitiannya lebih baik dan lebih lengkap lagi.

\section{Daftar Pustaka}

Azwar, S. (2012). Penyusunan Skala Psikologi edisi 2. Yogyakarta. Pustaka Pelajar

Fadli, R. P., Alizamar, A., \& Afdal, A. (2017). Persepsi Siswa tentang Kesesuaian Perencanaan Arah Karir Berdasarkan Pilihan Keahlian Siswa Sekolah Menengah Kejuruan. Konselor, 6(2), 74. https://doi.org/10.24036/02017627578-0-00

Falentini, F. Y., Taufik, T., \& Mudjiran, M. (2013). Usaha Yang Dilakukan Siswa Dalam Menentukan Arah Pilihan Karir Dan Hambatan-Hambatan Yang Ditemui. Konselor, 2(1), 310-316. https://doi.org/10.24036/02013211266-0-00

Hasanah, M., Denok, S. (2014). Penerapan Layanan Informasi Menggunakan Media Video Untuk Meningkatkan Pemahaman Terhadap Masa Depan Karir Siswa Kelas XI SMA Negeri 3 Lamongan. Jurnal BK UNESA. 4(3), $1-10$.

Hidayati, R. (2015). Layanan Informasi Karir Membantu Peserta Didik Dalam Meningkatkan Pemahaman Karir. Jurnal Konseling Gusjigang. 1(1), 1-10

Khairun, D. Y., Sulastri, M. S., \& Hafina, A. (2016). Kematangan Eksplorasi Karir Siswa. Jurnal Penelitian Bimbingan Konseling, 1(1), 1-23.

Komariah, N. (2016). Pemanfaatan Blog Sebagai Media Pembelajaran Berbasis Ict. Al-Afkar: Jurnal Keislaman \& Peradaban, 5(1). https://doi.org/10.28944/afkar.v5i1.111

Pemerintah Indonesia. (2006). Undang-Undang Republik Indoenesia No.20 Tahun 2003 Tentang Sistem Pendidikan Nasional. Lembaran RI Tahun 
2003 No.20. Jakarta. Direktorat Jenderal Pendidikan Islam Departemen Agama RI.

Pranoto, H., Wibowo, A., \& Atieka, N. (2017). Layanan Bimbingan Kelompok Mahasiswa Prodi BK Mengunakan Media ICT (Information and Communications Technology) Basis Social Media. Jurnal Mikrotik, 7(2), $14-24$.

Zulkaida, A., Kurniati, N. M. T., Retnaningsih, Muluk, H., \& Rifameutia, T. (2007). Pengaruh Locus of Control Dan Efikasi Diri Terhadap Kematangan Karir Siswa Sekolah Menengah Atas (SMA). PESAT (Psikologi, Ekonomi, Sastra, Arsitek \& Sipil), 2, 21-22. 